\title{
Application of New Energy Saving Technology and Materials in HVAC Design of Civil Buildings
}

Shengjie Guo ${ }^{*}$, Lin Ru

College of Civil Engineering and Water Resources, Heilongjiang Bayi Agricultural University, Daqing, 163319, China

DOI: $10.36348 /$ sjce.2020.v04i05.001 $\quad$ Received: 22.06 .2020 | Accepted: 30.06 .2020 | Published: 05.07 .2020

*Corresponding author: Shengjie Guo

\section{Abstract}

Under the background of rapid development of social economy and continuous progress of scientific information technology, new energy-saving technologies and materials have been widely used in building HVAC design, and promoted the development of China's architectural HVAC design field. The application of new energy saving technology and materials in building HVAC design can effectively reduce the energy consumption of building HVAC design and achieve the effect of energy conservation and environmental protection.

Keywords: new energy-saving technology; Civil construction;HVAC design; application.

Copyright @ 2020: This is an open-access article distributed under the terms of the Creative Commons Attribution license which permits unrestricted use, distribution, and reproduction in any medium for non-commercial use (NonCommercial, or CC-BY-NC) provided the original author and source are credited.

\section{INTRODUCTION}

In the field of modern architecture, HVAC design is an important part of it, which is related to water and heating and other links in the later stage of architectural engineering, and it is also a relatively basic part in architectural design. HVAC design plays a key role in the architecture design, but it also is the main part of the energy consumption in the building, and with the emergence of new energy conservation technology and materials, it is used in the design of the building HVAC, can very good reduce the loss of material resources in building HVAC design, realize the greening development of building HVAC design.
The significance of new energy-saving technology and materials in HVAC design

With the rapid development of China's national economy, the related energy consumption is also increasing constantly, among which the energy consumption in the building sector accounts for an important proportion. The development of the highenergy building sector will not only cause the continued waste of resources, but also have a certain impact on the development of social economy. The following is the HVAC design drawing of a civil building:

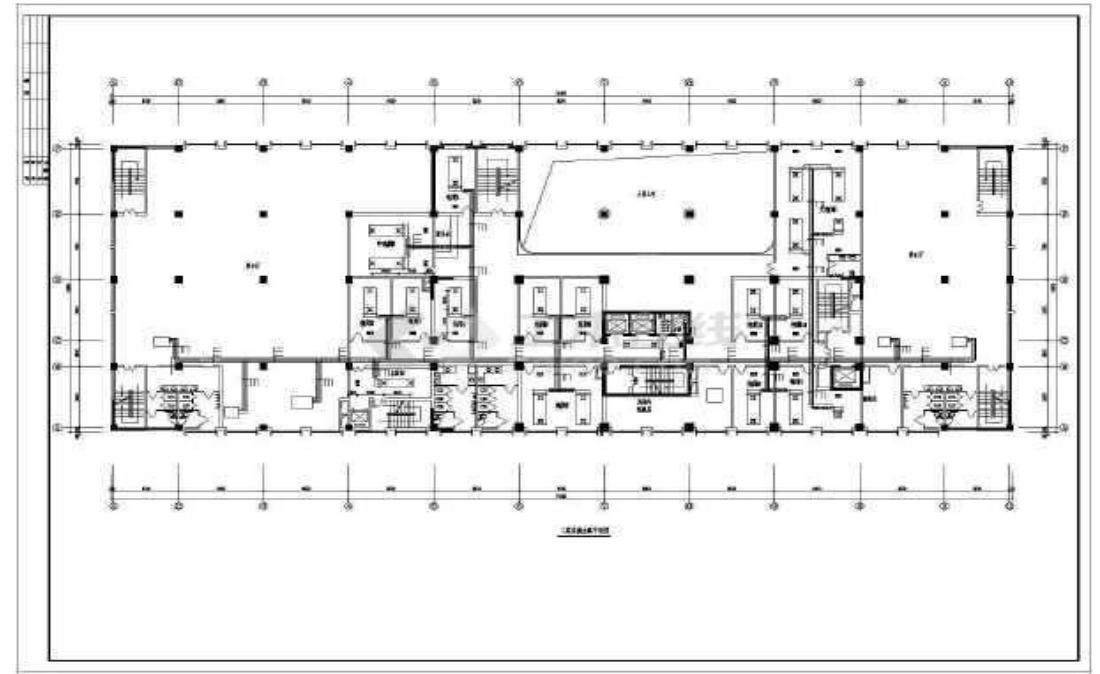


According to relevant data analysis, building energy consumption of HVAC design occupies a large proportion in the whole construction project, and is still in a continue to grow, it is to a certain extent caused the expansion of the contradiction between supply and demand of energy, especially the application in the civil building HVAC design more non-renewable resources, is not conducive to the protection of resources and the environment. Based on the investigation in the field of building HVAC design, it is found that the use of appropriate energy saving measures in building HVAC design can effectively reduce the consumption of resources in building HVAC design, achieve a certain goal of energy saving, and thus realize the green development of building HVAC design.

\section{Application of new energy saving technology and materials in HVAC design Application of new energy saving materials}

In recent years, the energy saving material widely used in the market is nanometer transparent heat insulation coating, especially building glass. The main characteristics of the nanometer transparent thermal insulation coating are: first, the mechanical performance is higher than the film thermal insulation material, nanometer transparent thermal insulation coating is larger than the film thermal insulation material. Nanometer conductive oxide has high film hardness and good luminosity according to its own unique principle. Second, new energy - saving materials are corrosion - resistant, aging - resistant and transparent. Nanometer particles have different effects on light, mainly absorption and reflection, thus improving the corrosion resistance and aging resistance of the coating. Because its size is much smaller than the wavelength of visible light, visible light reflects its transparency through particles. Third, the new energysaving materials have strong self-cleaning ability. The main characteristics of nanometer materials are large surface area, high activity rate and strong catalytic ability. Under the action of oxygen and ultraviolet radiation, nanometer materials show corresponding self-cleaning ability. Fourth, the price of new energysaving materials is relatively low, the price of new energy-saving materials is significantly lower than the price of transparent insulation film. Nanometer transparent thermal insulation coating is mainly hightech, which can deal with the transparency and thermal insulation of glass well. However, the application intensity of coating in our country is not widespread, so it is necessary to strengthen the application intensity of coating in the early stage of construction.

\section{Heat pump technology}

Heat pump rationally utilizes the natural heat energy to become the main heat source, and transforms the heat source compressor into the heat energy. Therefore, heat pump technology is widely used in heating and air conditioning industry. The main characteristic of heat pump technology is to make full use of the low-temperature heat energy of natural rivers and the low-temperature heat energy in daily life. At present, China's economic energy has achieved the improvement of energy supply equipment, maximum use of natural gas. Heat pump technology can produce the corresponding thermal energy and cooling effect, and can be applied in reverse under special circumstances to realize the common use of heat source and cold source. In addition, making full use of heat pump technology can reduce energy consumption and achieve air and environmental emissions. Heat pump technology can obtain better energy saving effect, improve the social benefits of enterprises, and promote the stable development of enterprises.

\section{Application of frequency conversion technology}

Green building layout and energy-saving design of air conditioning system should also pay attention to the application of flexible and advanced technology. For example, the application of frequency conversion technology should be highly valued. At present, heating and power regulator systems are widely used, but the application effect is not uniform, it is difficult to play strong energy efficiency. The power conversion technology application needs to be centered, and through further research, there is a better need to improve energy efficiency. The application of power grid construction air conditioning system applications is generally considered when automation technology assistance, the application of advanced electronic technology, most buildings in the air conditioning system load reduction, reflects this. The designer shall reasonably install the temperature and humidity induction device in the HVAC system and formulate scientific and reasonable control procedures to make the operation of the air-conditioning system more accurate and eliminate unnecessary loads.

Frequency conversion technology is an early green energy saving technology applied in HVAC. This can not only save resources effectively, but also improve the efficient use of resources, and play a role in protecting the environment and maintaining the balance of nature and ecology. Therefore, frequency conversion technology in HVAC design can show the green energy-saving effect, play a good role in the promotion. The application of frequency conversion technology makes a good adjustment to the internal environment of buildings, which is mainly reflected in two aspects: first, when the natural light intensity is enhanced, the adjustment unit of variable frequency strip also increases with the increase of lift output heat. Second, when there are more people in the building, starting the fan output heat automatically increases. It can be seen that the application of frequency conversion technology can effectively reduce energy consumption and achieve the effect of energy saving. The advantages of this technology are as follows: first, self-regulation through temperature change can not only meet users' needs, but also improve users' use efficiency and energy saving 
effect. Second, all energy-consuming facilities can be independently controlled, free from the influence and interference of any other factors.

\section{Rational application of cold storage technology}

The energy-saving design of HVAC system under the concept of green building can flexibly use energy-saving technology and effectively adjust the energy applied by it. In the case of refrigeration, for example, water freezes to form ice at the right time and is then cooled by melting ice. The application of low temperature technology not only effectively alleviates the power supply pressure of peak power consumption, but also reflects the strong energy efficiency. Relatively speaking, the energy consumption is low, and does not affect the indoor temperature regulation effect.

\section{Application of heat energy recovery technology}

Waste heat refers to the energy that is not fully utilized by the energy resource utilization equipment under certain economic and technological conditions, which is called severe waste heat or energy. There are a lot of waste heat resources in HVAC, which can be effectively recycled and used, and can obviously improve the operation efficiency of HVAC. According to the present situation, waste heat recovery and cold heat recovery are two commonly used technologies in heat energy machine. Using the working principle of the heat recovery device, the heat exchange between the air outlet and the listening water is realized. The condensation heat recovery and reuse technology is mainly based on the way of water recycling, which can recycle the waste heat and save energy at the same time, which is beneficial to environmental protection.

\section{Applications of hydraulic balancing devices}

Use hydraulic balancing device to ensure the hydraulic balance of air conditioning system. Manual cannot achieve hydraulic balance; you can take the hydraulic balance valve to control. In general, hydraulic valves have two kinds of walking and stopping, the actual application of its analysis. For example, when HVAC water waves are large, dynamic hydraulic balance can be used to control and adjust. In other cases, static hydraulic balance valves are generally used.

\section{CONCLUSION}

To sum up, the application analysis of new energy-saving technologies and new materials in folk building HVAC design is the theoretical representative of comprehensive utilization of human resources and plays an important role in future social resource planning. On this basis, give full play to the advantages of new energy-saving technologies and materials, realize the energy-saving and environmental protection of the overall design of air conditioning, and make comprehensive and effective use of urban resources. Therefore, the application of new energy-saving technology and materials to the HVAC design of civil buildings is a scientific and practical strategy to improve the utilization rate of social resources.

\section{REFERENCE}

1. Guo, J. (2017). Energy-saving Application of HVAC [J]. Engineering Technology Research, 8:110-112.

2. Xie, M., GUO, X.S. (2016). Application research of green Concept and Energy-saving Technology in HVAC Design [J]. Residential \& Real Estate, 27:49.

3. Wang, M. (2018). Application of new Energysaving technology and materials in HVAC Design of Civil Buildings [J]. Residential \& Real Estate, 11:141.

4. Liu, G. (2017). Discussion on key Points in HVAC Design of high-rise Civil Buildings [J]. Residential \& Real Estate, 3:83. 